\title{
MAGNETIC ABRASIVE FINISHING
}

\author{
Vishwanath Patil \\ Department of Mechanical engineering, Vishwabhararti Academy's College of Engineering, Ahmednagar, India \\ Prof. Jaydeep Ashtekar \\ Department of Mechanical engineering, Vishwabhararti Academy's College of Engineering, Ahmednagar, \\ India
}

\begin{abstract}
Magnetic abrasive finishing is a machining process where the tooling allowance is remove by media with both magnetic and abrasive properties, with a magnetic field acting as a binder of a grain. Such machining falls into the category of erosion by abrasive suspension and lend itself to the finishing of any type of surface. The possibility of finishing complex surfaces is a special benefit of this machining. Magnetic abrasive finishing process is most suitable for obtaining quality finish on metallic and non-metallic surfaces. Magnetic abrasive finishing used for complicated product finishing \& Roughness and tolerance band achieved that is difficult using conventional machine process. The product dimensional requirement easily possible with taking trial with MAF parameters.
\end{abstract}

\section{INTRODUCTION}

Various industrial applications require very high surface finish up to the range of nanometres or even above with the development of modern manufacturing trends. Presently, it is required that the parts, used in manufacturing semiconductors, atomic energy parts, medical instruments and aerospace applications, have a very fine surface roughness. Amongst them, vacuum tubes, wave-guides and sanitary tubes are difficult to be polished by conventional finishing methods such as lapping, because of their shapes. The technology for super finishing needs ultra clean machining of advanced engineering materials such as silicon nitride, silicon carbide, and aluminium oxide which are used in high- technology industries and are difficult to finish by conventional grinding and polishing techniques with high accuracy, and minimal surface defects, such as micro cracks. Therefore, magnetic abrasive finishing (MAF) process has been recently developed for efficient and precision finishing of internal and flat surfaces. This process can produce surface finish of the order of few nanometres. In addition, MAF possesses many attractive advantages, such as self-sharpening, self-adaptability, controllability, and the finishing tool requires neither compensation nor dressing.

\section{TYPE OF MAGNETIC ABRASIVE FINISHING}

\section{MAGNETIC ABRASIVE FINISHING WITH PERMANENT MAGNET}

Magnetic abrasive finishing (MAF) is one of the advanced finishing processes, which produces a high level of surface quality and is primarily controlled by a magnetic field. In MAF, the work piece is kept between the two poles of a magnet. The working gap between the work piece and the magnet is filled with magnetic abrasive particles. A magnetic abrasive flexible brush (MAFB) is formed, acting as a multipoint cutting tool, due to the effect of the magnetic field in the working gap. When inserting a cylindrical work piece in such a processing field giving revolution, feed and vibration in axial direction, surface and edge finishing are carried out by magnetic brush. In the application of ferromagnetic substance of work, for instance, work piece is also magnetized and the magnetic force acts on the top of the brush between the work piece and the abrasive grains resulting in pressing the abrasive grains to work surface. The MAF process removes a very small amount of material by indentation and rotation of magnetic abrasive particles in the circular tracks.

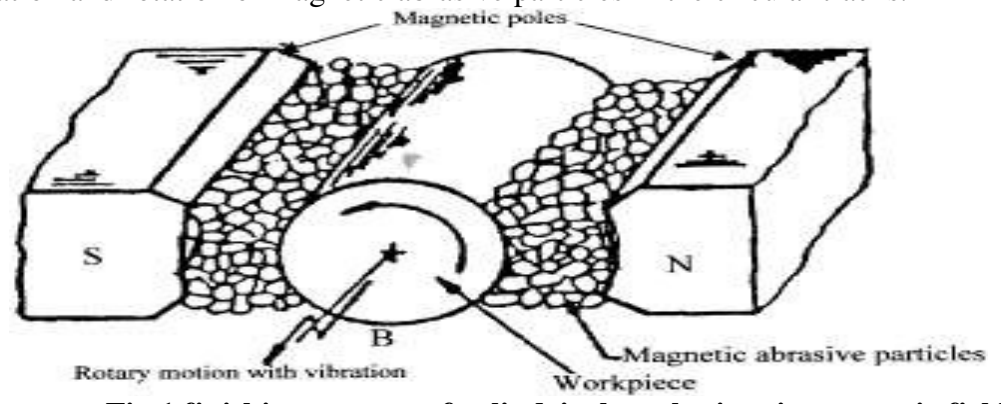

Fig.1 finishing process of cylindrical work piece in magnetic field 


\section{MAGNETIC ABRASIVE FINISHING WITH DIRECT CURRENT}

Magnetic abrasives introduced into the pipe are conglomerated at the finishing zone by a magnetic field, generating the finishing force against the inner surface of the tube. In the process, magnetic abrasive particles introduced into the work piece are attracted by the magnetic field and bear on the inner surface of the work piece. These particles join each other along the lines of magnetic force due to dipole-dipole interaction and form a Flexible Magnetic Abrasive Brush (FMAB) which pushes against the work piece surface and develops finishing pressure. This finishing pressure originates micro indentations in the work piece surface. The tangential force developed by FMAB is the major cutting force responsible for micro chipping. Abrasives generally rely upon a difference in hardness between the abrasive and the material being worked upon, the abrasive being the harder of the two substances. In MAF operation, work piece is kept between the two magnets. The magnetic poles $\mathrm{N} \& \mathrm{~S}$ were placed face to face with their axes crossing at right angle with a brass pipe in the configuration as shown in figure 2.The Magnetic field extends in the inner region of the pipe without regard to presence and absence of the pipe to the machined and actuates magnetic force to magnetic abrasive particles packed inside pipe. Abrasive particles can be used as un-bonded, loosely bonded or bonded. Bonded magnetic abrasive particles are prepared by sintering of ferromagnetic powder (iron) and abrasive powder at a very high pressure and manufacturing process employed determines surface finish level. Some processes are inherently capable of producing better surfaces than others. The processes recognized for good surface finish are honing, lapping, polishing and surface finishing. A schematic of experimental set up is shown in figure, which embodies the principles of internal finishing described in the previous section. The experimental setup has major components like electromagnet (10 k Gauss), control unit, D.C. motor, variable D.C. supply.

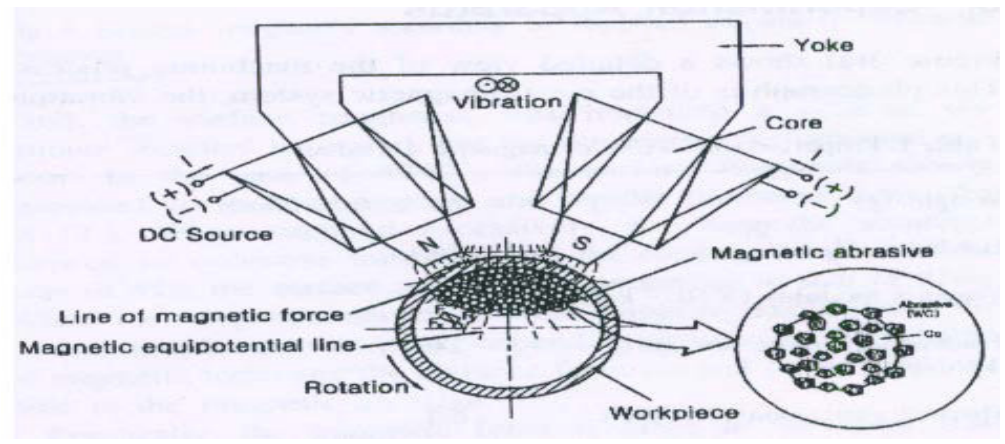

Fig.2 Schematic view of the internal polishing system using magnetic force and magnetic abrasives

\section{Magnetic Abrasive Finishing with Alternating Current}

The rotating magnetic field obtained by electrifying three coils arranged in the directions at intervals of 120 degrees with three phase AC current for internal finish cylindrical work pieces.

\section{MAGNETIC ABRASIVE FINISHING MATERIAL PREPARATION METHODS}

\section{SINTERING}

It is a method for making objects from powder, by heating the material in a sintering furnace below its melting point (solid state sintering) until its particles adhere to each other. Sintering is traditionally used for manufacturing ceramic objects, \& has also found uses in such fields as powder metallurgy.

\section{ADHESIVE BONDING:}

A special type of adhesive is required for providing a strong bond between magnetic and abrasive component. The amount of adhesive in mixture of abrasive and Ferro magnetic components was decided in such a way that adhesive completely wets the mixture and at the same time the mixture should not behave like a fluid.

\subsubsection{SIMPLE MIXED MAGNETIC ABRASIVES:}

In this technique of preparing magnetic abrasives, Iron powder and $\mathrm{SiC}$ powder is simply mixed without adding bonding material. It is believed that iron particle sandwich SiC particles and under the influence of magnetic field, the mixture causes abrasion action on the work piece surface. 
Novateur Publication's

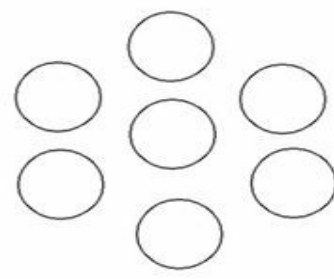

Iron powder

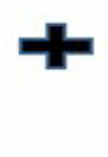

Abrasive

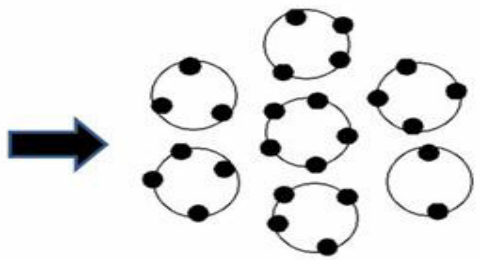

Magnetic abrasives

Fig.3 Basic material preparation

\section{CASE STUDY}

In this research Paper, a SS 305, SS 316 and brass cylindrical work piece was finished using a magnetic abrasive finishing process at different speed, magnetic flux density, hardness and work piece gap and corresponding to these parameter improvement in surface finish is investigated. The aim of this paper is to study maximum efficiency in terms of material removal rate. Magnetic abrasive finishing as an efficient tool for internal finishing of bent tubes. In this research a cylindrical work pieces was finish using a magnetic abrasive finishing process on a apparatus developed for carrying out testing work. The process principle and the finishing characteristics of magnetic abrasive finishing of cylindrical pipes using sintered magnetic abrasives are described in this research work. The sintered magnetic abrasive is a mixture of alumina abrasive and ferromagnetic particles. The alumina based sintered magnetic abrasives have been developed in sintering machine. The process parameters were the gap between work piece and magnet, rotational speed of work piece, magnetic flux density, hardness and the work piece gap. The improvement of surface roughness was achieved because the vibrational motion effectively removes unevenness in rotational direction and direction orthogonal to it.

Table 1.Experimental conditions of Work Piece

\begin{tabular}{|l|l|}
\hline Abrasive grain size & $120,150 \& 220$ grits $(106,75 \& 53 \mathrm{um})$ \\
\hline Magnetic pole & SS 400:Material \\
\hline Work piece & SS 304, SS316 \& Brass tubes \\
\hline Revolution & $80,95 \& 170 \mathrm{rpm}$ \\
\hline Magnetic abrasives & Aluminum oxide Al2O3, Ferrite particles \\
\hline Magnetic flux density & $3000,4000 \& 5000$ gauss \\
\hline Gap between work piece \& pole & $2,3 \& 4$ \\
\hline Work piece hardness & $45,50 \& 55 \mathrm{RC}$ \\
\hline Machining duration & $60,90 \& 120$ \\
\hline
\end{tabular}

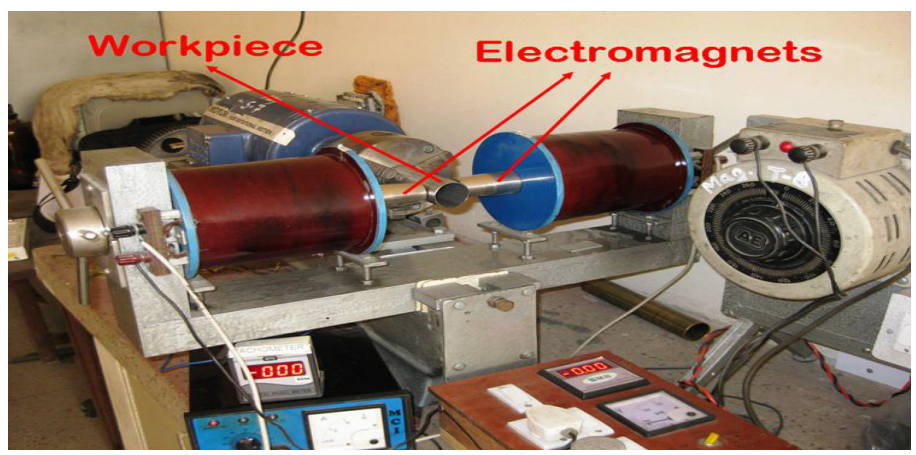

Fig.4 Experimental Setup of MAF

\section{EXAMINATIONS AND RESULTS}

\section{ROTATIONAL SPEED OF WORK PIECE}

In this study, the rotational speeds of 80,95 and $170 \mathrm{rpm}$ and the duration of machining of 60 minutes were experimented. It can be seen that the improvement in surface finish is more with higher rotational speed. The improvement in surface finish can be due to more abrasives that come in contact with the work piece during lower speed. 


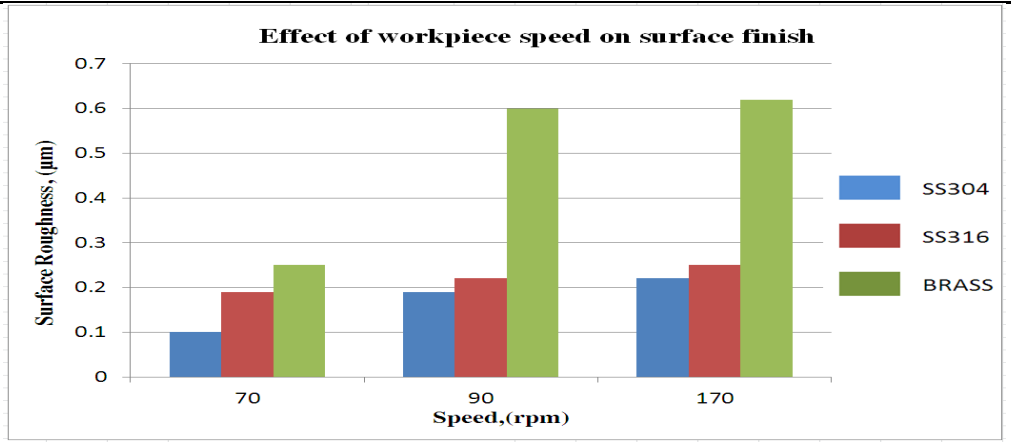

Fig.5 Work piece speed Vs Ra

\section{INFLUENCE OF MAGNETIC FLUX DENSITY}

On surface finish figure, illustrates the effect of magnetic flux density on surface finish. The flux density used in the experiments was $0.3,0.4$ and 0.5 tesla $(\mathrm{T})$ and the machining duration was 60 minutes. From the results, it can be noticed that the increase in flux density then improvement in surface finish this could be due to the abrasives with high magnetic field density, the movement of the abrasives is also redirected in the machining zone.

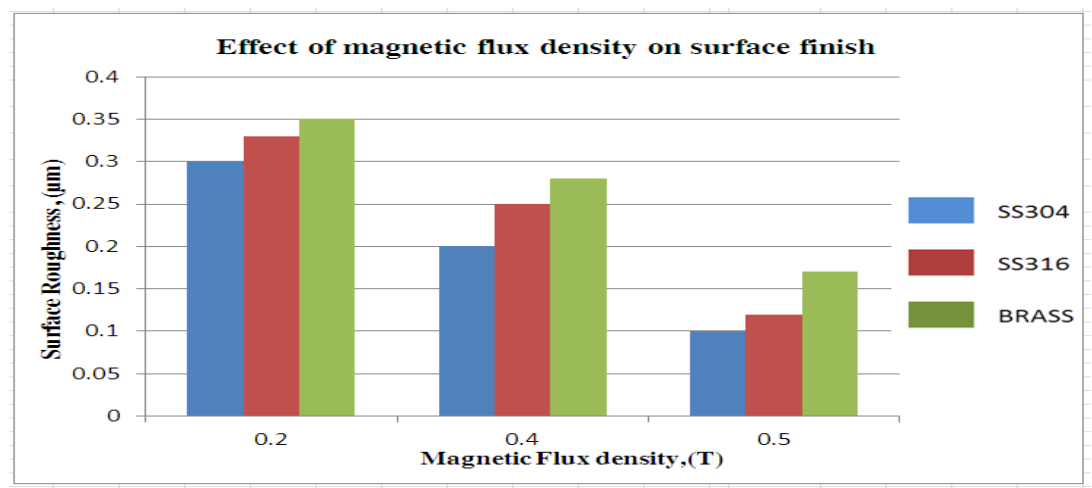

Fig.6 Magnetic flux density Vs Ra

INFLUENCE OF GAP BETWEEN WORK PIECE \& MAGNETIC POLE ON SURFACE FINISH:

The gap considered for the experimentation was 4,6 and $5 \mathrm{~mm}$ and the machining duration was 60 minutes. It can be seen that the work piece clearance of $5 \mathrm{~mm}$ with $\mathrm{Al} 2 \mathrm{O} 3$ abrasive grit contributed to an improvement in surface finish. Similar trend was noticed with $\mathrm{SiC}$ grits also.

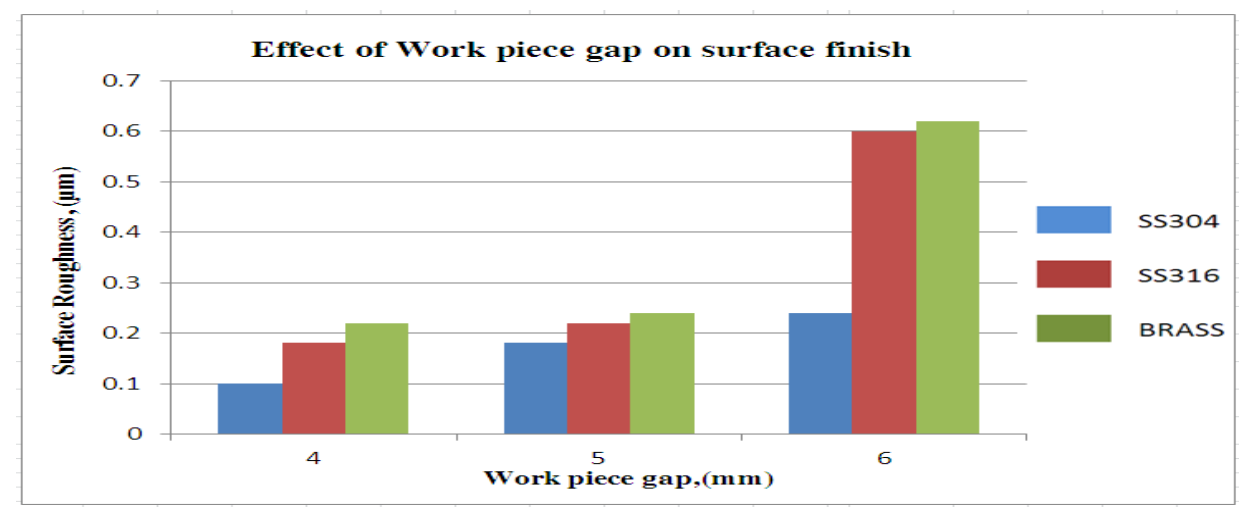

Fig.7 Work piece gap Vs Ra

\subsubsection{INFLUENCE OF WORK PIECE HARDNESS ON SURFACE FINISH:}

Turned work pieces hardened to 45, 50 and $55 \mathrm{RC}$ and ground to 0.2 to 0.6 ìm Ra are considered for this study. Large improvement in the finish is noticed on work piece with a hardness of $55 \mathrm{RC}$ with Al2O3and ferrite abrasives. 


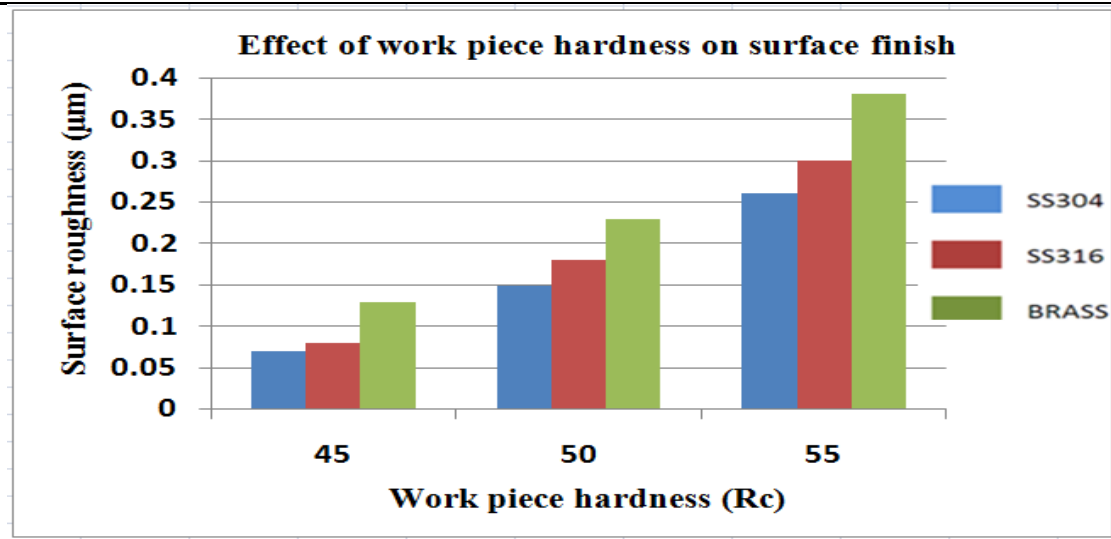

Fig.8 Work piece hardness Vs Ra

\section{CONCLUSION}

The magnetic abrasive finishing process combining the grinding, DE-burring and polishing process. The roughness and tolerance band of component achieved using control parameter Magnetic Abrasive Machining (MAM) for polishing of cylinder work piece was developed using available abrasives. The experimentation with these process parameters reduced the surface roughness value on a cylindrical component from an initial Ra value. These studies also indicated the need to consider the work piece initial roughness, apart from its hardness for achieving an improved finish on the work surface. Study shows that on various parameters improvement in surface finish is maximum in case of brass as compared to other materials.

\section{REFERENCES}

[1] "Magnetic Abrasive Finishing- A Review” By Harish Kumar, Sehijpal Singh, Pradeep Kumar IJERT Vol.2 Issue 3, March-2013.

[2] "To study the Effect of Various Parameters on Magnetic Abrasive Finishing" By Mithlesh Sharma, Devinder Pal Singh IJRMET Vol. 3, Issue 2, May-Oct 2013.

[3] "Study of Magnetic Abrasive Finishing in free-form surface operation using the Taguchi method" By ChingTien Lin, Lieh-Dai Yang, and Han-Ming Chow.

[4] "Study of Mechanically Alloyed Magnetic Abrasive in Magnetic Abrasive Finishing" By M.G.Patil, Kamlesh Chandra, P.S.Mishra IJS\&ERT Vol.3 Issue 2, October-2012.

[5] "Comparing the Magnetic Abrasives by Investigating the Surface Finish" By Rohit Rampal JEC\&AS Vol.1 No.1 October 2012.

[6] "Study on Magnetic Abrasive Finishing" By E. Hatano, M. Matsunaga Annals of the ClRP Vol. 3/1/Lm

[7] "Reducing Downtime of Repairing for Taper Roller Bearing By Magnetic Abrasive Finishing (MAF) Process" By Pawan Kumar Basera and Vijay Kumar Jain DOI: 10.7763/IJIMT.2013.V4.375

[8] "A Study of Various Techniques of Preparing Magnetic Abrasives" By Baljinder Singh* and Charanjeet Singh Sandhu ISSN: 2277-9655, November, 2014.

[9] "Micro machining of an STS 304 bar by magnetic abrasive finishing" By Ik-Tae Im1, Sang Don Mun1,* and Seong Mo Oh2 I.-T. Im et al. / Journal of Mechanical Science and Technology 23 (2009) 1982 1988.

[10] "Magnetic field assisted abrasive based micro-/nano-finishing" by V.K. Jain Journal of Materials Processing Technology 209 (2009) 6022-6038. 